\title{
A radicalização neoliberal e os processos de subjetivação com base no trabalho dos professores temporários (pss)
}

Everson Araujo Nauroski ${ }^{1}$

Maria Aparecida Bridi²

Resumo: O presente artigo analisa as condições de trabalho dos professores temporários do Paraná (PSS) em um contexto de radicalização neoliberal. Um processo que vem alcançando os serviços públicos, incluindo a educação. Insistimos no termo radicalização neoliberal, em vista de um movimento pendular regressivo em diversos países, erigido, em parte, pelo acirramento das políticas de desregulamentação da legislação trabalhista e a consequente precarização das condições de trabalho. Ao longo deste texto, será mostrado como isso tem ocorrido na realidade educacional paranaense. Para tanto, a metodologia envolveu a realização de entrevistas em profundidade com 9 professores, visitas a 4 escolas de Curitiba e Região Metropolitana, além do envio, por e-mail, de 112 questionários contendo questões abertas e fechadas. Os dados apurados revelaram que muitas das medidas e políticas implementadas possuem um viés neoliberal. Entre essas medidas, destacamos os contratos temporários, os processos de flexibilização dos vínculos de trabalho e a consequente precariedade das condições laborais nas escolas.

1 Centro Universitário Internacional Uninter - Curitiba - Brasil - eversonnauroski@gmail.com

2 Departamento de Sociologia e Programa de Pós-Graduação em Sociologia da Universidade Federal do Paraná (UFPR) - Curitiba - Brasil - macbridi@gmail.com 
Palavras-chave: Neoliberalismo. Trabalho docente. Precarização. Subjetivação.

\title{
The neoliberal radicalization and the processes of subjectivation from the work of temporary teachers (pss)
}

\begin{abstract}
This paper analyzes the working conditions of temporary teachers in Paraná (PSS) in a context of neoliberal radicalization. A process that has been reaching public services, including education. We insist on the term neoliberal radicalization, in view of a regressive pendulum movement in several countries, erected in part, by the intensification of the policies of deregulation of labor legislation and the consequent precariousness of working conditions. Throughout this text will be shown how this has occurred in the educational reality of Paraná. To do so, the methodology involved in-depth interviews with 9 teachers, visits to 4 schools in Curitiba and Metropolitan Region, and e-mailing of 112 questionnaires containing open and closed questions. The data found revealed that many of the measures and policies implemented have a neoliberal bias. Among these measures we highlight the temporary contracts, the processes of flexible working relationships and the consequent precarious working conditions in schools.
\end{abstract}

Keywords: Neoliberalism. Teaching work. Precariousness. Subjectivation.

\section{INTRODUC,ÃO}

Se, na década de 1990, Harvey (2003) anunciava a transição de um modelo de acumulação denominado fordista para um regime de acumulação flexível, hoje essa transição parece já ter ocorrido, como demonstram inúmeras pesquisas empíricas sobre as atuais configurações do trabalho. Entretanto, tal como no fordismo - que nunca foi um modelo homogêneo e tampouco desapareceu -, no contexto atual, quando o regime de acumulação flexível se tornou maduro, prevalecem as formas de trabalho, as relações de trabalho, modalidades contratuais e de mercados com características heterogêneas. Isto é, se mantém a dualização dos mercados de trabalho, uma característica do fordismo em países como o Brasil, que se expande na "era flexível", mas, diferentemente daquele contexto, agora se encontra plenamente revestido pelo signo do neoliberalismo. Que implicações isso tem para os trabalhadores? Como as relações de trabalho flexíveis avançam sobre a educação? Quais consequências o avanço neoliberal traz para os trabalhadores da educação no estado? São indagações que buscamos responder neste artigo, com base na análise de uma das maiores categorias de trabalhadores do 
Paraná, os professores das escolas estaduais, e que passa a conter em suas fileiras um número cada vez maior de professores flexíveis, isto é, aqueles contratados pela via Processo Seletivo Simplificado - PSS, que adentram à rede estadual de ensino na condição de contratados temporários da educação.

Conforme dados do Sindicato dos Trabalhadores em Educação Pública do Paraná (APP-Sindicato), a rede estadual de ensino possuía, em 2015, aproximadamente 100 mil professores ativos, sendo que, destes, mais de 30 mil estavam atuando como temporários PSS. Ao analisar o que significa ser um professor PSS, identificamos uma relação de desigualdade em relação aos professores com vínculo efetivo. Uma desigualdade que salta aos olhos frente à situação de instabilidade e insegurança no trabalho, no acesso negado ao plano de saúde, à carreira, aos vencimentos por titulação e ainda outras disparidades abordadas ao longo deste texto.

O presente artigo traz as reflexões suscitadas com base nos resultados de pesquisa junto aos professores temporários (PSS) realizada no Paraná. Nosso estudo ocorreu entre 2013 e 2014 e envolveu visitas técnicas a 04 escolas, entrevistas em profundidade realizadas com 09 professores, além da aplicação de 112 questionários que foram enviados e respondidos por e-mail. Esses instrumentos possibilitaram analisar a condição de trabalho desses professores e, ao mesmo tempo, adentrar pela seara de alguns dos problemas da educação paranaense. Dentre os objetivos desta pesquisa, buscamos refletir sobre as condições e relações de trabalho dos professores temporários, bem como suas implicações subjetivas para esses trabalhadores.

\section{O CONTEXTO E AS CONDIÇÕES DE TRABALHO}

No estado do Paraná, principalmente a partir da década de 1990, passou a predominar políticas neoliberais não só na economia, período de grande atração de empresas multinacionais com base em políticas fiscais (Bridi, 2005), mas também na condução da educação, objeto deste artigo. A partir dessa década, conhecida como a "década neoliberal", surgiram mudanças no quadro de contratação de professores do estado. Ocorreu um aumento progressivo no uso de formas de contratação flexíveis, caso dos professores PSS, que podemos afirmar como precárias. Conforme dados de Nogueira (2016), considerando uma média anual de 13.053, em 2007, contando com variações para mais e ou para menos em cada ano analisado, essas médias de contratação de PSS, em 2013, saltaram para 25.235, e 2014 contou com 23.376 professores PSS contratados, o que representou cerca $30 \%$ de contratados nessa modalidade. Desse modo, "no 
período analisado, a média de professores temporários no governo Requião (2007- 2010) foi de $22,79 \%$ e de $26,58 \%$ no governo Richa (2011 - 2014)" (Nogueira, 2016: 231). Essa quantidade expressiva de professores na modalidade contratação temporária tem relação com esse quadro neoliberal que se estabeleceu em diversas partes do mundo e no Brasil.

É preciso considerar algumas vantagens que esse tipo de contratação propicia ao Estado. Em um primeiro momento, o aspecto contábil é o mais evidente. Ao prolongar o uso da mão de obra temporária, evita-se integrar esses professores como efetivos, o que lhes garantiria, entre outros direitos, a progressão na carreira e o consequente aumento de seus ganhos salariais. Mas, atuando assim, a administração consegue mais do que economizar com a folha, interferir na organização e na ação coletiva desses trabalhadores. A categoria se divide entre professores efetivos e concursados (Quadro Próprio do Magistério-QPMs) e PSSs. Isso atinge a unidade do magistério, cujos reflexos são sentidos na capacidade de mobilização e organização de suas lutas.

A conjuntura que se estabeleceu com as políticas neoliberais colocou o mundo do trabalho na defensiva, atingindo os trabalhadores tanto do setor privado quanto do setor público. No Brasil, observa-se um processo de intensificação dessas políticas, sobretudo, e ainda de forma mais intensa, em governos que se associam às ideias do livre mercado e anti-estatais, caso de alguns governos estaduais. $\mathrm{O}$ embate maior tem sido travado em meio aos projetos de lei e votações que intencionam "reformar" a legislação trabalhista visando a sua "modernização", o que, na prática e no caso brasileiro, tem significado a perda de direitos e a aprovação de modalidades de contrato que fragilizam ainda mais os trabalhadores, como é o caso do trabalho intermitente e a terceirização irrestrita, cujo alcance atinge o setor público e privado em diferentes níveis. São situações que, no âmbito deste estudo, denominamos de radicalização neoliberal.

Esse quadro é indicativo de que a luta de classes alcançou um novo patamar, e demarca uma nova configuração, que, sob certos aspectos, tende a ser mais sutil e sofisticada, incorporando diferentes elementos do novo espírito do capitalismo nos termos de Boltanski e Chiapelo (2009). O embate está sendo travado no terreno político-ideológico visando à construção da hegemonia social. Nisso consiste predominantemente o caráter manipulatório do capitalismo contemporâneo, como também percebido por Ianni (2003) e Alves (2011), ao assinalar os discursos e práticas do mundo corporativo e suas estratégias em influenciar a mente e o coração de consumidores e trabalhadores.

No "novo espírito do capitalismo", a empresa "educa" com discursos e práticas em torno da "proatividade", da "integração", do "engajamento" da 
"polivalência e da multifuncionalidade". Dessa forma, como afirmaram Dardot e Laval (2016: 21), o "neoliberalismo emprega técnicas de poder inéditas sobre as condutas e as subjetividades", e, assim, os princípios neoliberais passam a se constituir também como ideologia pessoal e como uma nova razão do mundo. E isto é uma condição que se estende também para uma parcela da classe trabalhadora (dos empregados públicos) dentro de empresas estatais, como demonstrou Braunert (2018), quando eles assumem os discursos neoliberais.

Para Byung-Chul Han (2015), está ocorrendo uma mudança de paradigma na cultura organizacional do mundo empresarial, uma mudança que não se restringe ao mundo corporativo, mas, nesse, tende a ser mais intensa. $\mathrm{O}$ ideal de um bom funcionário, como aquele que cumpre seus horários e obrigações parece estar superado. Segundo Han, o objetivo das empresas é, cada vez mais, alcançar o engajamento de seus colaboradores. Um projeto que tem sido realizado, segundo esse autor, pela implementação da cultura do desempenho, no qual não escapam também os trabalhadores públicos. Na interpretação de Han (2015: 23-24), a "sociedade do século XXI não é mais a sociedade disciplinar, mas uma sociedade de desempenho. Também seus habitantes não se chamam mais 'sujeitos da obediência', mas sujeitos de desempenho e produção". Nesse sentido, a lógica operativa do sistema econômico passou a compreender que é mais vantajoso trabalhar com a positividade do desempenho do que com a negatividade da disciplina. Todavia, a cultura disciplinar não foi superada, visto que os dispositivos institucionais, apoiados por novas ferramentas tecnológicas, visam a promover o engajamento dos trabalhadores nas empresas estão em franca progressão e novos mecanismos de controle continuam a disciplinar os trabalhadores.

Trata-se, como assinala Han, de um poder fazer, sem que se abandone o dever que se espera de "colaborador" engajado, no qual,

[...] o sujeito de desempenho continua disciplinado. Ele tem atrás de si o estágio disciplinar. O poder eleva o nível de produtividade que é intencionado através da técnica disciplinar, o imperativo do dever. Mas em relação à elevação da produtividade não há qualquer ruptura; há apenas continuidade (Han, 2015: 26).

Paralelamente à velha cultura disciplinar, com seus mecanismos de controle e punição, vai se consolidando uma nova forma de pensar a subjetividade dos trabalhadores. Uma rápida consulta aos programas de educação corporativa indica 
a predominância de temas ligados à motivação, desenvolvimento pessoal e profissional, gestão da carreira, qualidade de vida no ambiente de trabalho. No bojo dessas mudanças, surgem novos cargos e funções que têm a missão de implementar ideias e práticas de desempenho, como a figura curiosa do gestor da felicidade.

Elementos dessa cultura transcendem o mundo corporativo e se materializam também nos discursos da cultura escolar, conforme analisou Nauroski (2014), em sua tese, ao mostrar que é comum nas escolas, os discursos imbuídos de nobres valores, com expressões como "aqui funcionamos como uma família" ou, ainda, "se todos fizerem a sua parte teremos bons resultados". Frases repetidas por membros das equipes gestoras estampadas em cartazes em corredores e sala dos professores. Soma-se a isso o uso de textos vindos da secretaria da Educação, o órgão gestor da educação estadual, para orientar e subsidiar o trabalho dos professores nas escolas. Cinco desses textos, os quais analisamos, buscavam instar os professores a assumir seu "protagonismo", a fazer a "diferença", a buscar a "excelência" em seu trabalho, com o discurso de que é preciso "escolher" o lado da educação, ou "todos" pela educação, sem, contudo, dar margem a reflexões sobre as condições de trabalho ou sobre as políticas educacionais adotadas.

Essas e outras situações, observadas no âmbito deste estudo, coadunam-se com os alertas de Han de que o sujeito do desempenho se entrega ao que encontra em um sistema de "livre coerção" para a maximização de seu desempenho. Esse contexto que prevalece a livre coerção "é mais eficiente que uma exploração ao do outro, pois caminha de mãos dadas com o sentimento de liberdade. O explorador é ao mesmo tempo o explorado" (Han, 2015: 29-30). Isso lembra a conduta dos gestores dentro das organizações escolares, que mesmo sendo trabalhadores assumem a função de controle dentro da escola. O professor, por sua vez, com excesso de trabalho e busca pelo desempenho, encontra-se enredado em um processo de autoexploração.

Além das ações no plano ideológico junto aos professores em seu fazer pedagógico, existem medidas tomadas pela administração pública que atingem concretamente os professores em seu trabalho. Em 2011, por exemplo, face aos fechamentos de turmas, uma mãe de aluno escreveu uma carta aberta à imprensa denunciando a situação e relatando a orientação dada às escolas para que houvesse unificação de turmas com fechamento de salas, criando turmas com 45 alunos. Essa mãe fez o seguinte registro: "quero informar que vou levar isso à público a partir desse momento como mãe. Como disse minha filha, é tanta conversa e tantos alunos que não sabemos nem quem está falando". Uma turma com 45 alunos implica em uma piora na condição de trabalho do professor e na consequente precarização do trabalho. Isso precariza o trabalho e 
também a educação, pois, como vimos na pesquisa empírica, há professores que trabalham em muitas escolas e com diversas disciplinas a ministrar.

A tendência de precarização é ilustrada em matérias jornalísticas no estado: "Em crise de gestão, governo Richa manda fechar salas de aula no Paraná". Ou, ainda, "Professores estão perdendo aulas, horários não batem direito e alunos sofrem em salas superlotadas. Uma situação que estaria ocorrendo em todo estado". Em outra matéria, podemos ler a chamada: "Em Curitiba, comunidade vai às ruas contra fechamento de salas de aula". No texto, a reportagem destaca: "A modificação do porte das escolas, como quer o governo Richa, mexe com as condições de trabalho dos educadores, bem como influencia na aprendizagem dos alunos. Ao eliminar turmas, sem discussão com a comunidade escolar, provoca-se a superlotação nas salas e dispensa de funcionários e professores. Concomitantemente, cai a qualidade do ensino"s.

São situações noticiadas e vivenciadas no interior das escolas pelos professores, que potencializam o estresse, afetando a saúde dos professores, conforme mostrou Nauroski (2014: 203), no qual "mais de 50\% dos professores pesquisados afirmam que ficaram doentes em decorrência de suas atividades na docência”. Alguns problemas de saúde são recorrentes nessa categoria, como estresse, nervosismo, ansiedade, depressão, pânico. Relacionando as informações, há uma convergência de aspectos sobre situações de exaustão emocional, cansaço crônico, desânimo e insatisfação. Isso nos leva a supor que talvez muitos estivessem acometidos da Síndrome de Burnout4 sem que soubessem.

É preciso lembrar que, no caso dos professores PSS, a situação tende a se agravar ainda mais. Para atingir um número mínimo de aulas e poder assinar um contrato, os professores se obrigam a aceitar a fragmentação de sua carga-horária, tendo que trabalhar em até cinco escolas diferentes, em bairros diferentes. Por serem temporários, não têm a preferência na escolha das aulas e nem das escolas, uma prerrogativa dos professores efetivos (QPM), ou seja, os PSS ficam com o que sobra. Muitas escolas estão em regiões periféricas, muitas vezes, com problemas de infraestrutura, falta de recursos, clientela com diversos problemas, desde situações de violência na escola e em seu entrono até deficit severos de aprendizagem. Estes são fatores que tornam a atividade docente dos PSS um desafio diário. $\mathrm{O}$ fato de terem que transitar em mais escolas para ministrar suas aulas faz com que não tenham horário de descanso nem tempo

3 Estas matérias estão disponíveis em: <http://www.esmaelmorais.com.br/2014/o2/em-crise-governo-richa-manda-fechar-salas-de-aula-no-parana/> . Acesso em: 11 set. 2019.

4 Tal suposição se deve à recorrência com que apareceram nos relatos e nos questionários as queixas de estresse, cansaço, exaustão, desânimo, perda do sentido em relação ao trabalho. 
de se alimentar adequadamente. Esse quadro de adversidades tem reflexos na saúde desses professores, conforme demonstrou Nauroski (2014).

A relação entre precariedade, mal-estar, sofrimento e adoecimento em relação à categoria dos professores está consolidada em diferentes pesquisas que demonstram os nexos causais, como assinalado por Frigotto (1995), Lourencetti (2004), Oliveira (2003) e Esteve (1999).

Somadas às condições de contratação flexíveis observadas no Paraná, encontram-se as reformas educacionais ocorridas no Brasil, que foram pautadas pela lógica neoliberal na implementação de medidas que direcionam as mudanças para atender os interesses do mercado. Conforme assinalado por Silva (1997: 12), de um lado, no processo de reestruturação neoliberal buscou-se "atrelar a educação institucionalizada aos objetivos estreitos de preparação para o local de trabalho". Para o autor, no léxico liberal, "trata-se de fazer com que as escolas preparem melhor seus alunos para a competitividade do mercado nacional e internacional". Mas isso principalmente com o fito de "utilizar a educação como veículo de transmissão das ideias que proclamam as excelências do livre mercado e da iniciativa". Conforme o autor, houve um esforço de mudanças curriculares "não apenas como objetivo de dirigi-lo a uma preparação estreita para o local de trabalho, mas também com o objetivo de preparar os estudantes para aceitar os postulados do credo liberal." (Silva, 1997: 12).

No caso da educação paranaense, objeto deste estudo, as ações do órgão gestor parecem ter como objetivo conformar subjetivamente os professores para aceitarem essa responsabilização. A reação frente a essa tentativa vem dos professores concursados que estão protegidos por sua estabilidade, e se sentem mais seguros para fazer enfrentamentos nas escolas. Por outro lado, muitos professores, no âmbito desta pesquisa, aceitavam como verdade a retórica de que os professores podem "salvar", sendo necessário "vestir a camisa" da educação na escola.

Observamos que os professores que mais sofrem em relação à sua profissão, tanto entre os efetivos quanto os PSS, são aqueles mais comprometidos com o seu trabalho, que nutrem ideais e valores em relação à educação. Entre esses professores, são comuns as afirmações de "querer mudar a sociedade, ou pelo menos algumas cabeças", que ser "professor é ter uma missão". São afirmações que denotam um sentido simbólico da docência. Para esses professores, existe um compromisso ético e social ligado à profissão.

Parece existir uma clara intenção do órgão gestor em mobilizar discursos e práticas visando a construir consensos e aceitação por parte dos professores 
em relação ao que é oferecido nas escolas e na rede estadual de ensino. O discurso oficial é que o governo faz o que pode pelas escolas e professores, que é preciso medidas de ajustes nos gastos para se manter em dia os compromissos, inclusive com a folha de pagamentos. Ao invés de reclamações e críticas, todos deveriam fazer sua parte. Manter as escolas funcionando requer sacrifícios de todos. É importante destacar, portanto, que a escola não é um bloco homogêneo. Pelo contrário, na escola também se encontram expressas todas as contradições da sociedade capitalista e de uma classe trabalhadora também dividida, não apenas devido ao tipo de vínculos dos contratos, mas em termos ideológicos, de assunção às teses neoliberais. Há resistência de um lado, pois se trata de uma categoria com tradição em organização e combatividade, mas também conformismo e certa "adesão" aos discursos neoliberais.

O plano discursivo segue em duas direções. A primeira de um "dever ser escolar", em uma idealização do trabalho dos professores, e em uma segunda, de desresponsabilização do agente público em garantir qualidade na educação pública como direito social por meio de políticas públicas. A justificativa de que "estamos fazendo o que é possível, os recursos são limitados" tanto serve para exigir "sacrifícios" pela educação, quanto ajudam a embasar outra retórica bem conhecida dos defensores do Estado-mínimo, a de que os problemas e a pouca qualidade nos serviços públicos é resultado da gestão pública incompetente. Em alguma medida essa retórica serve para endossar iniciativas privatistas dos serviços públicos, entre eles a educação (Gentili, 1998).

Destacamos, no Paraná, o caso emblemático quando o governo de Jaime Lerner (1995-2002) criou o Paraná educação, uma empresa de direito privado para atuar no gerenciamento da educação do estado, podendo contratar e dispensar funcionários, bem como decidir sobre conteúdos pedagógicos a serem ensinados nas escolas da rede. Na prática, foram medidas de privatização da educação pública que só não avançaram mais em função das críticas e mobilizações do sindicato. Ou seja, pela resistência dos trabalhadores da educação.

Em face do exposto, as reações dos professores, de modo em geral, oscilam em duas direções, uma certa competição individual para conseguir suas aulas e contratos, e, ainda, na forma de denúncias ao sindicato sobre diversas situações, duas de modo recorrente, tratamento desigual no ambiente de trabalho e "reserva" de aulas por parte de diretores. Ainda na tentativa de resistir, são muitos os professores que encontraram alento em suas adversidades, criando ou fazendo parte de grupos de apoio como forma de buscar apoio, trocar informações e unir forças. 


\section{DIFERENTES FACES DA PRECARIZAÇÃO E SUAS IMPLICAÇ̃̃ES SUBJETIVAS}

Em função de seu vínculo precário, os professores PSS vivenciam cotidianamente o medo e a insegurança em relação à possibilidade de conseguirem ou não um contrato como professor temporário, ou de ter seu contrato rescindido caso um professor efetivo seja transferido para sua escola e solicite suas aulas. Sim, isso é possível. O direito de um, como a ordem de serviço que permite a remoção justificada de um professor efetivo, passa a ser o pesadelo dos professores PSS, que não possuem nenhum dispositivo de proteção em seu contrato, prevendo situações assim. Ou seja, mesmo assinando um contrato, o professor PSS não tem segurança de que este será cumprido integralmente no prazo estabelecido, que costuma ser de 12 meses. Essas e outras situações tornam o trabalho dos professores um expediente de incertezas, no qual o planejar a vida financeira e assumir compromissos econômicos de médio e longo prazo ficam obstaculizados. Soma-se a essa situação a disputa individual dentro da categoria, visto que se estabelece uma concorrência por disciplinas, por horários, por escolas com melhor infraestrutura e melhor clientela. De certa forma, esse aspecto competitivo corrobora a análise de Sennett (1999), em sua obra sobre a corrosão do caráter, em que, em situações de competitividade crônica, a moral pode enfraquecer e, na luta pela sobrevivência, e as fronteiras entre certo e errado podem ficar turvas.

Diante do exposto, é possível afirmar que existe uma divisão na categoria dos professores, sendo de um lado os professores do Quadro Próprio do Magistério - QPM, concursados e com estabilidade, e do outro os PSS, que atuam na rede estadual com contratos temporários. Na prática, não ocorre uma convergência de interesses da categoria. O prolongamento, por parte do Estado, no uso de formas precárias de contrato de trabalho atinge o magistério, fragilizando sua capacidade de articulação e luta, visto que o governo utiliza desse trabalhador flexível: "Sempre usam os PSS para enfraquecer as lutas. Pode reparar. Sempre sai uma conversa como o governo quer acabar com os PSS", ou que "vai reduzir os PSSs" etc. (Professora T. C. Grupo dos professores PSS do Paraná. Rede social. ${ }^{5}$

As estratégias governamentais e de seus órgãos gestores ${ }^{6}$ da educação têm surtido efeitos negativos entre os professores, ameaçando muitas das conquistas do magistério estadual. No governo estadual, claramente de orientação neoliberal, Beto Richa, algumas medidas ilustram a conjuntura desfavorável aos

5 Ver sobre isso em Nauroski (2014).

6 Referimo-nos como gestores àqueles que têm o poder de decisão sobre as políticas educacionais do Estado. 
professores, o que pode ser verificado como a redução da hora-atividade. Ou seja, a partir de 2017, a cada 20 horas (horas-aula) os professores tinham 7 horas para planejamento, com a mudança passaram a ter 5 horas. Essas duas horas a menos impactaram em jornada de trabalho, gerando uma reclamação generalizada por parte dos docentes que viram seu tempo de planejamento e organização diminuídos e, consequentemente, mais quantidade de trabalho não pago.

A contribuição de Linhart nos ajuda a pensar a realidade dos professores PSS, existindo correlações entre as análises desenvolvidas neste texto e o que a autora denomina de precarização subjetiva, uma forma de minimizar a capacidade dos trabalhadores de resistir e se opor, criando-se um tipo de

precariedade subjetiva para que os trabalhadores não se sintam à vontade no trabalho nem entre eles, para que não possam desenvolver redes de cumplicidade e de apoio com os colegas, com a hierarquia, nem com seus clientes, a fim de que sintam sempre a corda esticada e fiquem mais receptivos às injunções que visam aumentar a rentabilidade de seu trabalho. Essa lógica se expressa ainda melhor no setor público (Linhart, 2011: 3).

Este é um fenômeno que tem afetado os trabalhadores na aceitação das ideologias institucionais, naquilo que se traduz nos discursos e práticas que orientam e materializam a cultura organizacional para que se engajem nas metas e objetivos da organização como forma de garantir seus empregos. Situação semelhante observada no âmbito que circunscreve os PSS, visto que, não possuindo os mesmos direitos, com um contrato de trabalho flexível e de fácil rompimento, acabam, na prática, submetendo-se às condições precárias de trabalho, o que, não raro, geram sofrimento e adoecimento desses professores.

A preocupação de terem que "andar no fio da navalha" dificulta as relações mais duradouras, inclusive junto aos estudantes, afetando o processo educativo. A rotatividade, em função da perda de suas aulas para os professores efetivos, ou da desistência pelas condições precárias, impede a criação de vínculos, e a energia dispendida no trabalho se dissipa. Além disso, encontram-se fragmentados, pois seus interesses não são coincidentes - ou não se coadunam - com os professores estatutários. Os professores PSS atuam no vácuo, "nas sobras" deixadas pelos estatutários.

O quadro descrito anteriormente se insere em um cenário ainda maior da generalização de situações de degradação do trabalho, conforme indicado por Antunes (2007), ao analisar os processos de intensificação do trabalho e a criação de situações de penosidade no ambiente laboral. As formas de racionalização aplicadas, a polivalência, as mobilidades sistemáticas, os enquadramentos 
cada vez mais estritos "das atividades e do tempo passado no trabalho com avaliações e objetivos atribuídos pela hierarquia são cada vez mais limitantes” (Linhart, 2011: 3). Conforme a autora,

a padronização das atividades, [a] diminuição dos meios, [a] individualização que encontramos em diferentes campos visariam manter os assalariados em estado de insegurança e de dependência. Nas situações de trabalho não industriais, são modalidades de organização e de gerenciamento de inspiração taylorista que enquadram cada vez mais a atividade de trabalho. Trata-se ao mesmo tempo de diminuir os custos, mas também de expropriar os trabalhadores do domínio de seu trabalho e da capacidade de interpretar sua finalidade e seus fundamentos (...) (Linhart, 2011:3).

Os desdobramentos da degradação do trabalho se propagam aos trabalhadores da educação e, de modo ainda mais problemático, aos docentes PSS, pelas razões já assinaladas anteriormente. A desigualdade entre os dois grupos de docentes coloca, de um lado, os protegidos, que, inclusive, possuem um sindicato; e do outro, os menos protegidos, que vivem a instabilidade contratual, fazendo com que muitos docentes se submetam a situações de flagrante desrespeito e humilhação, conforme se observa no registro a seguir:

Quando cheguei na escola, tivemos uma reunião. O diretor então falou só para o grupo dos professores PSS: 'olha, vocês não são nada aqui, vocês estão na minha mão, vão fazer o que eu determinar, se não, já sabem, não precisa ficar nessa escola. Ficamos assustados, sem saber o que pensar. Foi falando um monte de coisa. Ninguém disse nada na hora, todo mundo ficou com medo. Não deu pra entender o porque daquela atitude. Me senti muito mal com aquilo. Do nada receber ameaça! Foi uma humilhação. Depois o pessoal comentou que o diretor era um grosso mesmo, uma pessoa autoritária, já tinham até feito abaixo assinado para tirá-lo (Professora PSS, Núcleo Bairro Novo, Curitiba, 2014).

Esse relato demonstra o constrangimento imposto por um gestor da escola - diga-se, um trabalhador - ao professor temporário e reforça a fragmentação, que tende a enfraquecer a categoria. O vínculo precário de trabalho faz com que os PSS não se sintam seguros nas escolas onde trabalham. Além disso, há questões ligadas ao próprio trabalho educativo, diálogos firmes com a direção da escola, defesa de posicionamentos, concepções, justificativas de opções metodológicas, recortes de conteúdo, enfim, aquilo que se atribui como prerrogativa da docência, aos professores PSS, são ações problematizadas, por vezes até 
impossibilitadas aos PSS. O mesmo se aplica aos enfrentamentos comuns junto aos alunos, às famílias, na cobrança de responsabilidade, sendo situações que colocam em xeque a ideia de autonomia e independência dos professores.

A pressão por assujeitar os PSS e enfraquecer a luta coletiva por melhores condições de trabalho da categoria chega ao extremo de serem proibidos, pelos gestores, de participar de greves ou paralizações. Nesse sentido, o órgão gestor responsável pela educação, por meio de seus núcleos regionais, escreveu aos diretores da rede paranaense de ensino, para que advertissem os PSS do risco que estariam correndo de ter seus contratos rescindidos caso aderissem à paralisação em maio de 2014. Podemos acompanhar o e-mail enviado às escolas:

Atendendo ainda a dúvidas que surgiram a SEED/GRHS informar que: Com relação ao Professor PSS, conforme preconiza a Lei nº 108 de 2005, artigo $\mathrm{n}^{\circ} 17, \$ 1^{\circ}$, estará sujeito à rescisão de contrato o profissional que faltar por mais de 7 (sete) dias consecutivos;

- Quanto ao profissional em estágio probatório, de acordo com o artigo $\mathrm{n}^{\circ} 43$ da Lei ${ }^{\circ}$ 6174/1970, a assiduidade é um dos requisitos necessários para a efetivação do profissional no cargo.

Atenciosamente, (...) Chefe do NRE - Londrina (Texto disponibilizado em rede social dos professores PSS do Paraná, 2014).

Em outros trechos do e-mail, o órgão gestor, para forçar os PSS e os professores em estágio probatório a manterem a escola em funcionamento, a não aderirem à greve, citam a legislação e usam demagogicamente o discurso do direito à educação. Se, de fato, houvesse preocupação real com o direito a uma educação e qualidade, não haveria fechamento de salas e superlotação de turmas, laboratórios de informáticas fechados, bibliotecas sucateadas, falta de recursos, inclusive de giz, conforme relatado pelos professores.

Em face dessas e outas limitações, a escola não deixa de representar um espaço de contradição, um campo em disputa, palco de interesses divergentes. Alunos e familiares reivindicam a escola como espaço de direito. Professores tomam a escola como espaço de luta e cidadania, inclusive quando intentam fechar suas portas, como ação simbólica de sua força.

Conforme já indicado, em 2015, mais de 30 mil professores da rede eram temporários PSS, uma condição que dificultou reagir às situações de pressão e abuso para não aderirem às mobilizações de greve da categoria. Outras situações rebaixam a importância dos PSS como profissionais qualificados. Dispender um tratamento desigual em relação aos direitos e carreira, pois os PSS ficam fora do plano de saúde, não têm direitos a progressões, nem a estabilidade, não 
ganham por titulação e quase todos os anos ficam até três meses sem receber, em função do fim do seu contrato e do início das aulas do próximo ano letivo. São elementos que formam uma conjuntura desfavorável à organização e luta coletiva dos professores.

É preciso ressaltar, contudo, que ao mesmo tempo em que a categoria se fragiliza, surgem novas modalidades de organização e formas de afirmação e defesa. A página em rede social dos docentes PSS do Paraná, por exemplo, possui quase mais de 35 mil membros, e tem se revelado um espaço de diálogo, trocas e articulação desses trabalhadores. Cumpre duas funções, pois ao mesmo tempo que possibilita a articulação destes, sendo espaço de diálogo e de trocas, também pressiona o sindicato da categoria em relação às suas pautas. Nesse sentido, o próprio sindicato, face ao grande número de PSS, mesmo considerando esta forma de contratação precária, viu-se desafiado a também atentar para as condições desses professores. E, nesse sentido, viu-se compelido a ampliar o escopo de suas ações. Nas paralisações que ocorreram em 2015, a APP-Sindicato apresentou, em sua pauta, a defesa dos PSS, para que pudessem ganhar pela titulação de especialista, ter direito à assistência de saúde e garantia de manutenção dos seus contratos. Uma reivindicação negada pela administração.

Apesar das divisões observadas, trata-se de uma categoria que se esforça para se articular e mobilizar seus coletivos. Os professores foram protagonistas de importantes greves e ações no âmbito do Paraná, com claros enfrentamentos face à perda de direitos e a mudanças que impactam negativamente as condições de trabalho.

Uma conjuntura que reforça a análise de Wenzel (1991), para quem a categoria dos professores, cada vez mais, assemelha-se à dos proletariados. Apresentam-se em uma massa de trabalhadores coletivos espalhados pelos diversos sistemas e redes de ensino, que vêm perdendo progressivamente o controle sobre o processo de produção do ensino, pela junção e acumulação, incompatíveis com as prerrogativas próprias da docência e dos processos pedagógicos, algo que desqualifica seu trabalho no aspecto em que outrora definia, a saber, a autonomia e a independência de sua práxis como educador, como trabalhador intelectual (Wenzel, 1991).

Em meio às condições de trabalho limítrofes, emergem significações ambivalentes na vida laboral dos PSS, o que tem implicado em processos de subjetivação que chamamos de negativa, com manifestações de sofrimento e adoecimento, conforme analisado por Nauroski (2014), ao constatar que mais de $50 \%$ dos professores pesquisados adoeceram em função de seu trabalho. No entanto, os professores resistem. Na busca por espaço e dignidade, os 
professores buscam encontrar sentido e alento para continuar sua jornada na solidariedade entre seus pares, no reconhecimento por parte de seus alunos, ou ainda na formação de redes de apoio dentro e fora das escolas (Nauroski, 2014).

\section{CONSIDERAÇÕES FINAIS}

A partir da década de 1990, as mudanças que vêm sendo implementadas no mundo do trabalho se orientam pela radicalização da lógica neoliberal. Sobretudo, duas situações ilustram o recrudescimento das políticas neoliberais: as reformas na legislação trabalhista e as mudanças nos regimes previdenciários, que nos últimos anos têm provocado, em diversos países, reações das classes trabalhadoras, ao se contrapor a essas medidas e defender seus direitos.

Além de interferir no campo jurisdicional, as investidas do capital reorganizam o trabalho social em diferentes campos e realidades. A implementação de processos de flexibilização, desregulamentação e toyotização ganham materialidade diferenciada em diferentes esferas do trabalho, envolvendo empresas do setor privado e público. Os modelos de gestão cada vez mais se articulam por discursos e práticas que assegurem a contenção de gastos, maximização de recursos e aumento de resultados e produtividade. Isso não deixa de ter implicações perniciosas sobre o conjunto dos trabalhadores, conforme vem sendo fartamente documentado pela Sociologia do Trabalho.

No campo da educação e no recorte deste estudo, a conjuntura que envolve os professores PSS é adversa, acarretando diferentes efeitos sobre esses trabalhadores, como o mal-estar, o sofrimento e o adoecimento em função das condições precárias de trabalho. Apesar das adversidades, observamos situações em que os docentes acabam por aderir aos discursos de engajamento no trabalho, assumindo-se como os primeiros responsáveis pela "causa da educação".

As tentativas de reação desses professores, em face dos problemas que enfrentam, estão concentradas no mundo virtual na página do Facebook dos Professores PSS do Paraná. Esse espaço em rede social tem se mostrado um recurso importante pela sua abrangência, dinamismo e velocidade. Uma força dos precários, frente ao descaso do Estado que insiste em mantê-los nessa condição, ou ainda, na oposição à força da direção da escola, que os trata com discriminação. Falar da resistência dos professores temporários com base em seu grupo na rede é entender que existe uma conexão entre o mundo virtual e o mundo real, em uma dialética complexa e de complementaridade. $\mathrm{O}$ que acontece no mundo virtual gera implicações no mundo real e vice-versa. Assim, entre as ações de resistência dos professores PSS, o espaço virtual também apresenta potencialidades. 
Atualmente, a página dos professores conta com milhares deles em todo estado, tendo como uma das características desse grupo a troca de informações de interesse mútuo, links de livros, eventos para professores, cursos gratuitos, editais, leis, artigos de temas afins, avisos gerais e das escolas, matérias, notícias, pedidos de ajuda, de informação sobre onde existem aulas disponíveis, quais cidades são melhores para se trabalhar, quais têm mais oferta ou necessidades de professores etc. Desabafos, críticas, protestos e repúdios formam o conjunto diverso de conteúdo do rol de informações que circulam no grupo.

Sob muitos aspectos, esse grupo tem contribuído, por meio dos seus diversos membros, para criar um espaço de pertencimento, de apoio e afirmação, no qual são reforçados laços em relação à identidade e ao trabalho dos professores. Nesse espaço, encontramos as muitas manifestações dos PSS refletindo sobre seu trabalho, suas condições contratuais, problemas comuns e seus estados emocionais.

Se, por um lado, constatamos um peso subjetivo maior envolvendo as situações de sofrimento entre os PSS, por outro, foi possível constatar ações e comportamentos de resistência, de afirmação e realização no trabalho. No entanto, permanece no horizonte das possibilidades imaginar se no curso da história da educação paranaense os professores temporários PSS conseguirão encontrar novos caminhos e estratégias de luta e reconhecimento do seu trabalho.

Por fim, o estudo ora apresentado, a radicalização neoliberal e os processos de subjetivação com base no trabalho dos professores temporários (PSS) revelou indícios de que a doutrina neoliberal adentrou ao campo das subjetividades, e mesmo uma categoria tradicionalmente intelectualizada como as dos professores tem tido dificuldades de resistir à ideia geral, de que frente aos problemas de ordem pública e coletiva, como é o caso dos processos de precarização das condições de trabalho nas escolas, as alternativas devem ser individuais. Esta é uma ideia que vem ganhando corpo nas representações sociais, e ao que nos parece, contribui para enfraquecer e desestimular ações de cunho social, política e coletiva.

\section{Referências}

ALVES, Giovanni. Trabalho e subjetividade: o espírito do toyotismo na era do capitalismo manipulatório. São Paulo, Boitempo Editorial, 2011 (168).

ANTUNES, Ricardo. O séc. XX e a era da degradação do trabalho. In: SILVA, José Pereira da Org. Por uma sociologia do séc. XX. Organização por José Pereira da Silva. São Paulo, Annablume, 2007, pp. 21-35. 
BOLTANSKI, Luc; CHIAPELLO, Eve. O novo espírito do capitalismo. São Paulo, Editora WMF Martins Fontes, 2009.

BRAUNERT, Mariana Bettega. Emprego público, racionalidade privada? Um estudo sobre o trabalho em companhias de economia mista do Paraná. Tese de doutorado. Universidade Federal do Paraná, 2018.

BRIDI, Maria Aparecida da Cruz. Sindicalismo e trabalho em transição e o redimensionamento da crise sindical. Dissertação de mestrado. Universidade Federal do Paraná, 2015.

CASTELLS, Manuel. Sociedade em Rede - A Era da informação. Economia, sociedade e cultura, v. 3. São Paulo, Paz e terra, 1999, p. 411-439.

ESTEVE, José M. Mudanças sociais e função docente. In: NÓVOA, A. (Org.). Profissão Professor. Porto, Porto Ed., 1995.

DARDOT, Pierre; LAVAL, Christian. A nova razão do mundo. São Paulo, Boitempo, 2016 (416). FRIGOTTO, Gaudêncio. Educação e crise do capitalismo real. São Paulo, Cortez, 1995 (240). GENTILI, Pablo A. A. A falsificação do consenso: simulacro e imposição na reforma educacional do neoliberalismo. Petrópolis, RJ, Vozes, 1998 (145).

HAN, Byung-Chul. Sociedade do cansaço. Trad. de Enio Paulo Giachini. Petrópolis, RJ, Vozes, 2015.

HARVEY, David. Condição pós-moderna: uma pesquisa sobre as origens da mudança cultural. São Paulo, Ed. Loyola, 2003.

IANNI, Octavio. Enigmas da modernidade mundo. $3^{\text {a }}$ ed. São Paulo, Civilização Brasileira, 2003.

LOURENCETTI, Gisele do Carmo. Mudanças sociais e reformas educacionais: repercussões no trabalho docente. Tese de Doutorado. Faculdade de Ciências e Letras, Universidade Estadual Paulista, Araraquara, 2004.

LINHART, Daniele. Entrevista com Danièle Linhart. Revista Trabalho, Educação e SAÚDE, Rio de Janeiro, v. 9 n. 1, pp. 149-16o, mar./jun.2011.

NAUROSKI, Everson Araujo. Trabalho docente e subjetividade: a condição dos professores temporários (PSS) no Paraná. Tese de Doutorado. Programa de Pós-Graduação em Sociologia, Universidade Federal do Paraná, 2014.

OLIVEIRA, Dalila Andrade. As reformas educacionais e suas repercussões sobre o trabalho docente. In: OLIVEIRA, Dalila Andrade (Org.) Reformas educacionais na América Latina e os trabalhadores docentes. Belo Horizonte, Autêntica, 2003.

SENNETT, Richard. A corrosão do caráter: as consequências pessoais do trabalho no novo capitalismo. Rio de Janeiro, Record, 1999.

SILVA, T. T. A 'nova' direita e as transformações na pedagogia da política e na política da pedagogia. In: GENTILI, Pablo; SILVA, T. T. (Orgs.). Neoliberalismo, qualidade total e educação. 5. ed. Petrópolis, RJ, Vozes, 1997. 
SOUZA, Marcelo Nogueira. Políticas públicas de educação no paraná: as condições de trabalho de professores temporários e o efeito-território na alocação de docentes como variáveis de análise. Tese de doutorado. Universidade Federal do Paraná, 2016.

WENZEL, Renato Luiz. O professor e o trabalho abstrato: uma análise da (des)qualificação do professor. Florianópolis: Dissertação (Mestrado em Educação). Programa de Pós-Graduação em Educação, Universidade Federal de Santa Catarina, 1991.

Recebido em: 25/08/2018

Aprovado em: 04/07/2019

\section{Como citar este artigo:}

NAUROSKI, Everson Araujo e BRIDI, Maria Aparecida. A radicalização neoliberal e os processos de subjetivação com base no trabalho dos professores temporários (pss) Contemporânea - Revista de Sociologia da UFSCar, v. 9, n. 3, set.- dez. 2019, pp. 899-916. 